\title{
p53, apoptosis and axon-guidance molecules
}

\author{
H Arakawa ${ }^{\star, 1}$ \\ ${ }^{1}$ Cancer Medicine and Biophysics Division, National Cancer Center Research \\ Institute, 5-1-1 Tsukiji, Chuo-ku, Tokyo 104-0045, Japan \\ * Corresponding author: H Arakawa, Cancer Medicine and Biophysics Division, \\ National Cancer Center Research Insitute, 5-1-1 Tsukiji, Chuo-ku, Tokyo 104-0045, \\ Japan. Tel: + 81-3-3547-5273; Fax: + 81-3-3546-1369; \\ E-mail: harakawa@gan2.res.ncc.go.jp
}

Received 22.11.04; accepted 24.1.05; published online 01.4.05 Edited by P Mehlen

\begin{abstract}
The p53 tumor-suppressor gene regulates apoptosis through the transcriptional activation of its target genes. The expression of the axon-guidance molecule UNC5B (also designated p53RDL1), which is a receptor for netrin-1, is directly regulated by $\mathrm{p} 53$. In the absence of netrin-1, UNC5B mediates p53-dependent apoptosis. Conversely, in the presence of netrin-1, p53-induced apoptosis is inhibited through the signaling pathway activated by the interaction between netrin-1 and UNC5B. A number of other molecules that are involved in axon guidance are inactivated in human cancers and are also regulated by $\mathrm{p} 53$. These findings suggest a close link between axon-guidance molecules and tumorigenesis.
\end{abstract}

Cell Death and Differentiation (2005) 12, 1057-1065.

doi:10.1038/sj.cdd.4401601; published online 1 April 2005

Keywords: p53; tumor suppressor; cancer; apoptosis; UNC5B; netrin-1

Abbreviations: DCC, deleted in colorectal cancer; DAPK, death-associated protein kinase; NRAGE, neurotrophin receptor-interacting melanoma-associated antigen homolog; $\mathrm{PI} 3 \mathrm{~K}$, phosphatidylinositol-3-kinase; ROBO, roundabout; $\mathrm{LOH}$, loss of heterozygousity

\section{Introduction}

p53, mutated in over $50 \%$ of all human cancers, may be considered to be the most important tumor-suppressor gene. p53 encodes a transcription factor that exerts its physiological functions by binding to a specific sequence within its target gene and activating its transcription. ${ }^{1,2}$ So far, a number of p53-target genes have been identified, which have a wide variety of effects in the cell. ${ }^{2,3}$ Thus, p53 is likely to regulate a variety of functions in response to different cellular stresses. Modifications of the p53 protein have been implicated in this regulation. ${ }^{2,3}$ In particular, the Ser46 phosphorylation of p53 is thought to play an important role in the activation of p53dependent apoptosis. ${ }^{4}$

Although various activities are regulated by p53, p53regulated apoptosis is believed to be the most important for tumor suppression. ${ }^{5}$ A number of excellent studies have attempted to understand the mechanism of p53-dependent apoptosis. These reports have suggested that the mitochondrial and the death-receptor apoptotic pathways play a key role in the process. ${ }^{5}$ However, identification of a number of p53-regulated genes clearly indicated that there are many p53-regulated apoptotic genes that are not involved in these two major pathways, implying that the mechanism for p53-dependent apoptosis still remains to be fully elucidated.

In the developing nervous system, migrating cells and axons are guided to their targets by chemotaxis. Members of four protein families (netrins, semaphorins, ephrins and slits) are involved in this process. ${ }^{6}$ Netrins, slits and some semaphorins are secreted molecules, whereas ephrins and other semaphorins are expressed at the cell surface. Several transmembrane receptors have been identified for each of these cues, including deleted in colorectal cancer (DCC), neogenin and UNC5H (rodent and human UNC5H receptor) for netrins; roundabout (ROBO) receptors for slit proteins; neuropilin and plexin for semaphorins; and Eph receptors for ephrins. These molecules involved in the four pathways have important roles in neural development and differentiation.

The concept of 'dependence receptors' was recently proposed by Bredesen et al. ${ }^{7}$ and Mehlen and Bredesen. ${ }^{8}$ DCC is a receptor for netrin-1 that has been shown to regulate apoptosis as a dependence receptor. ${ }^{9}$ In the absence of netrin-1, DCC induces apoptosis, whereas DCC-induced apoptosis is blocked in the presence of netrin-1. Thus, DCC might be a conditional tumor suppressor that is dependent on netrin-1. Similarly, UNC5H has also been shown to act as a dependence receptor that regulates apoptosis. ${ }^{10}$ Surprisingly, one of the UNC5H molecules was directly regulated by the tumor suppressor p53. ${ }^{11}$ In addition, its ligand, netrin-1, was also a direct target for $p 53$. These findings have provided a new perspective on the role of the p53-regulatory system in apoptosis.

\section{Tumor Suppressor p53 and Apoptosis}

Since its discovery, p53 has been a central player in the cancer research field, and much attention has been paid to this molecule by oncologists because it is frequently mutated in human cancers. Crucially, p53 encodes a transcription factor that binds to the specific sequences of its target genes and activates their transcription. p53 therefore exerts its physiological functions through the transcriptional activation of target genes. So far, a number of p53-target genes have been reported including $p 21 / W A F 1,{ }^{12} \mathrm{Bax}^{13}{ }^{13}$ IGF-BP $3,{ }^{14}$ $B A / 1,{ }^{15}$ GADD $45,{ }^{16}{ }^{16} 53 R 2^{17}$ and MDM2. ${ }^{18}$ The products of these genes have diverse functions including cell-cycle arrest, 
apoptosis, DNA repair, angiogenesis, immune response, axon-guidance, transcription, nucleotide metabolism and ubiquitin ligase activity. Although cell-cycle arrest and DNA repair are likely to be key functions in tumor suppression, apoptosis is believed to play a vital role in preventing cells from undergoing malignant transformation by eliminating damaged cells. ${ }^{5}$ Several excellent studies have attempted to clarify the mechanism of p53-dependent apoptosis, and a number of p53-target genes have been identified that have relevant roles. Currently, two pathways are known to function in p53-regulated apoptosis (Figure 1). ${ }^{5}$ The first is the mitochondrial pathway, which involves many p53-target genes including $\mathrm{Bax}^{13}{ }^{13}$ p3AIP1, ${ }^{4}$ Noxa $^{19}{ }^{19}$ Puma, ${ }^{20,21}$ APAF $1,{ }^{22} P I G 3,{ }^{23} P O X,{ }^{24} A L D H 4,{ }^{25} F D X R^{26}$ and CABC1. ${ }^{27}$ Recently, a direct role for p53 in this pathway was inferred from its localization within mitochondria (Figure 1). ${ }^{28}$ The second is the death-receptor pathway, in which Fas $^{29}$ and Killer/DR $5^{30}$ have been identified as the p53-target genes that mediate this pathway. Several additional target genes that are not directly involved in these pathways have also been shown to mediate p53-dependent apoptosis.

Why does p53 regulate multiple apoptotic genes as its transcriptional targets? A recent study has provided a clue to help answer this question. ${ }^{31}$ This study examined how p53 exerted transcriptional regulation on several of its apoptosis-related-target genes, in various mouse tissues, in which genotoxic stress had been induced by gamma irradiation. Interestingly, the results indicated striking tissue specificity with distinct regulation of p53-inducible genes in different cells and tissue compartments. For example, p53-dependent induction of Puma occurred in the splenic white pulp, whereas Noxa was induced in the red pulp. Thus, p53 appears to regulate distinct targets in different tissues or cells. This indicates that there might be tissue- or cell-specific regulation of individual targets, functions or pathways by $\mathrm{p} 53$. This finding clearly suggests that p53 might regulate its target genes in a tissue- or cell-specific manner, and must therefore regulate a number of different apoptotictarget genes.

Recently, UNC5B was reported to be a direct target gene for p53 that mediates p53-dependent apoptosis. ${ }^{11}$ UNC5B is also known to be a dependence receptor that regulates apoptosis either positively or negatively depending on its interaction with netrin-1. ${ }^{10}$ UNC5B-induced apoptosis seems to be independent of the mitochondrial and death-receptor pathways. This might therefore represent a third pathway for p53-dependent apoptosis (Figure 1). The present review focuses on this p53regulated dependence-receptor pathway and discusses the close link between axon-guidance molecules and tumorigenesis.

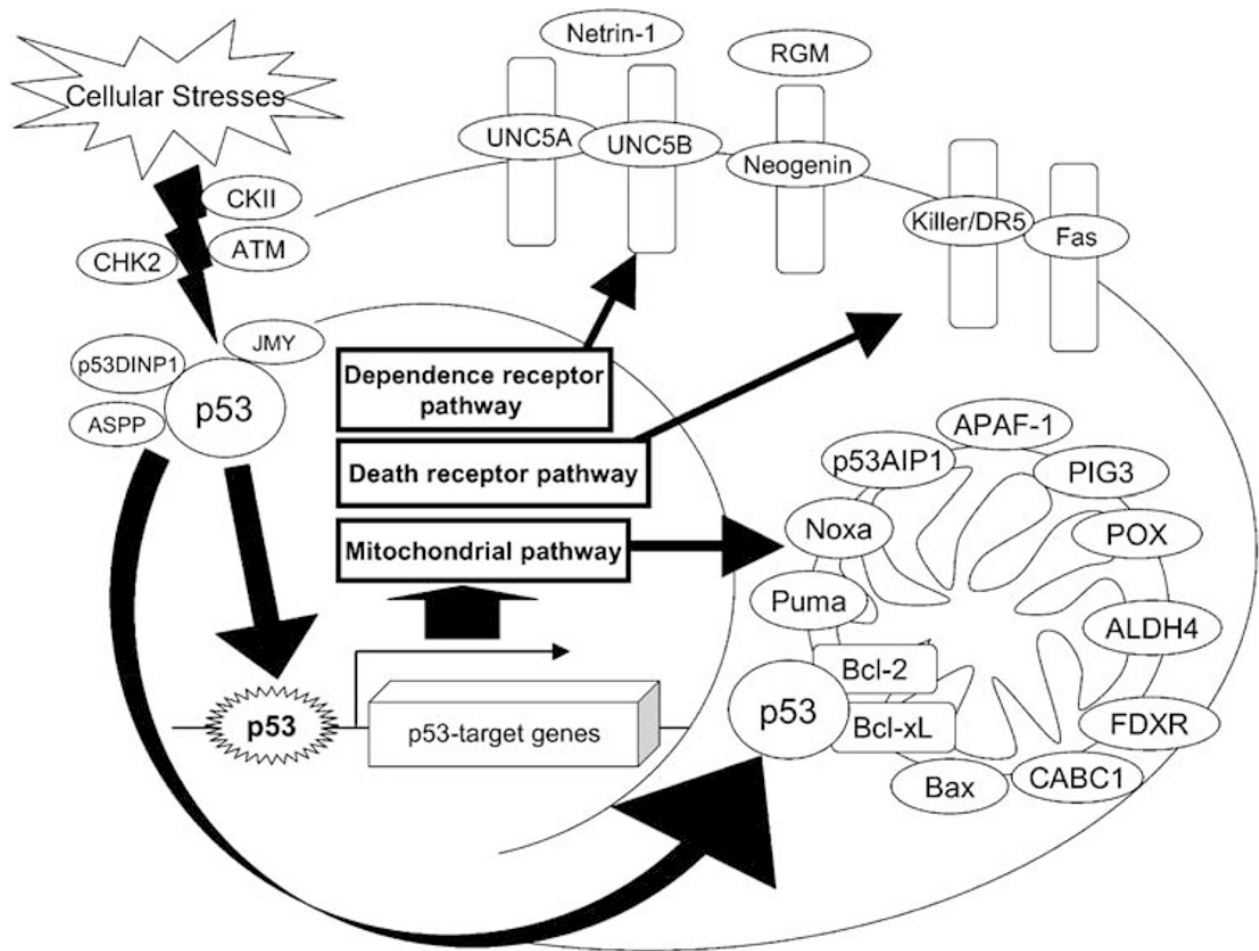

Figure 1 p53-regulated apoptotic pathways. p53 is activated in response to various cellular stresses. Initially, kinases (such as ATM, ${ }^{83,84} \mathrm{CHK}^{85}$ and CKIII6) sense the stresses, and then phosphorylate the p53 protein at various sites (such as Ser15, Ser20 and Ser46) through interactions with cofactors (such as p53DINP1, ${ }^{87}$ JMY ${ }^{88}$ and $\left.A S P P^{89}\right)$. These upstream molecules modify the p53 protein, leading to the activation of p53. The activated p53 binds to specific sequences in apoptotic-target genes and activates their transcription. Several p53-regulated apoptotic-target genes have been identified and are divided into two major pathways: the mitochondrial and death-receptor pathways. Bax, Noxa, Puma, p53AIP1, PIG3, POX, ALDH4, FDXR, CABC1 and APAF-1 belong to the former group, and KillerIDR5 and Fas belong to the latter. UNC5B was recently found to be involved in p53-regulated apoptotic pathways, implying the involvement of dependence receptors in a third pathway. UNC5A, NTN1 (encoding netrin-1), NEO1 (encoding neogenin) and RGMA (encoding RGM) might be involved in this pathway. Furthermore, a transcription-independent p53-regulated apoptotic pathway was identified, in which p53 itself localizes to mitochondria and directly regulates the mitochondrial antiapoptotic molecules Bcl-2 and $\mathrm{Bcl}-\mathrm{xL}$ 


\section{p53 and UNC5B}

UNC5B is one of four related receptors for netrin-1 (UNC5A UNC5B, UNC5C and UNC5D), all of which are type-I transmembrane proteins that belong to the Unc5 family. ${ }^{32}$ Rodent UNC5H1, UNC5H2 and UNC5H3 were designated by sequence homology to be orthologs of Caenorhabditis elegans UNC5, which has a role in axon guidance along with the ortholog of netrin-1, uncoordinated 6 (UNC6). ${ }^{33}$ Rodent $\mathrm{UNC} 5 \mathrm{H} 1, \mathrm{UNC} 5 \mathrm{H} 2$ and $\mathrm{UNC5H} 3$ are orthologs of human UNC5A, UNC5B and UNC5C, respectively. Hereafter, the term $\mathrm{UNC} 5 \mathrm{H}$ is used to refer to $\mathrm{UNC} 5 \mathrm{H} 1, \mathrm{UNC} 5 \mathrm{H} 2, \mathrm{UNC} 5 \mathrm{H} 3$, UNC5A, UNC5B and UNC5C. All of these proteins have two immunoglobulin-like domains and two thrombospondin-like repeats in the extracellular region, along with a zonula occludens 1 (ZO-1) domain and a death domain in the intracellular region. ${ }^{10,32}$ Recently, the sequences of human UNC5D and rodent UNC5H4 were obtained and deposited in the database (DDBJ/EMBL/GenBank). However, so far, nothing is known about the function of these molecules.

UNC5B contains a death domain in its intracellular region and acts as a dependence receptor. ${ }^{10}$ This protein's intracellular region also contains a classical caspase-cleavage sequence, DXXD. As has been demonstrated for rodent UNC5H2, ${ }^{10}$ UNC5B is cleaved by caspase-3 in vitro ( $\mathrm{N}$ Kitamura and $\mathrm{H}$ Arakawa, unpublished data), and a point mutation at the cleavage site inhibits UNC5B-induced apoptosis in vivo. ${ }^{11}$ The deletion of the death domain of UNC5H2, which is the rodent ortholog of human UNC5B completely abrogates UNC5H2-induced apoptosis, implying that the death domain is essential for this process. ${ }^{10}$ The mechanism of UNC5B-induced apoptosis is still largely unknown. However, two proteins are thought to be involved in the signaling pathway. The first is the death-associated protein kinase (DAPK), which might mediate UNC5H2induced apoptosis by interacting with the death domain of UNC5H2. ${ }^{34}$ The second is the neurotrophin receptor-interacting melanoma-associated antigen (MAGE) homolog (NRAGE), which is known to interact with UNC5H1. ${ }^{35} \mathrm{NRAGE}$ has also been suggested to mediate UNC5H-induced apoptosis.

It has recently been shown that the transcription of UNC5B is directly regulated by $\mathrm{p} 53 .^{11} \mathrm{~A}$ p53-binding sequence is located within intron 1 of the UNC5B gene. In response to genotoxic stresses, UNC5B expression was induced in a p53-dependent manner in the colorectal cancer cell line HCT116-p53 ${ }^{+/+}$and the breast cancer cell line MCF7 (both of which contain wild-type (wt) p53), but not in the colorectal cancer cell line HCT116-p53 ${ }^{-1-}$ and the lung cancer cell line H1299-p53 ${ }^{-/-}$. This implies a role for UNC5B outside neural tissue development, in the physiological function of p53. Interestingly, the inhibition of UNC5B expression by antisense oligonucleotides markedly blocked p53-dependent apoptosis. ${ }^{11}$ These data suggest that UNC5B mediates p53-dependent apoptosis by acting as a direct transcriptional target for $\mathrm{p53}$, in cells other than neural tissue. The mechanism proposed would involve p53 activating the transcription of UNC5B in response to cellular stresses and UNC5B then localizing to the cellular membrane, where its intracellular region is cleaved, releasing the peptide containing the death domain, which then interacts with DAPK and/or NRAGE (Figure 2). Finally, this process

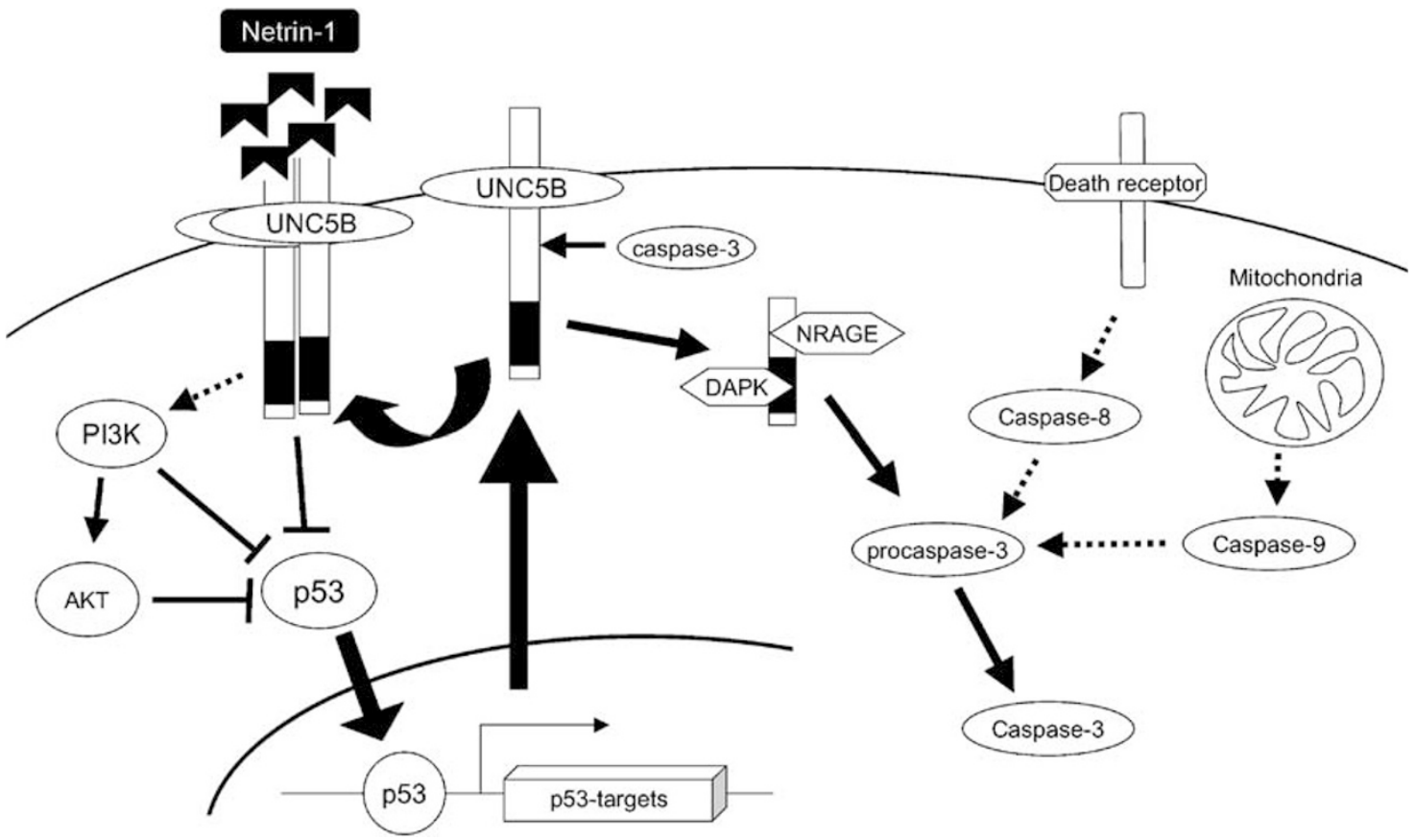

Figure 2 Pro- and antiapoptotic signaling pathways from UNC5B and netrin-1. In the absence of netrin-1, UNC5B induced by p53 localizes at the cell membrane and is cleaved at the intracellular region, releasing the peptide containing the death domain. This peptide might interact with DAPK and NRAGE, resulting in the activation of caspase-3 and apoptosis induction. This pathway is likely to be independent of the mitochondrial and death-receptor apoptotic pathways. Conversely, in the presence of netrin-1, binding to UNC5B induces its homodimerization, thus blocking the caspase cleavage. In addition, UNC5B sends a survival signal either directly, or through the activation of PI3K and AKT, in order to block p53-dependent apoptosis 
would activate caspase-3, leading to apoptotic cell death. Similar to DCC, this pathway is likely to be independent of the death-receptor and mitochondrial pathways (Figure 2).

\section{p53 and Netrin-1}

Netrins were initially identified through the genetic analysis of nematodes with mutations in the UNC6 gene. These animals exhibit defects in the guidance of commissural and motor axons. ${ }^{36,37}$ Netrin-1 is the vertebrate homolog of UNC6, implying that it functions as a chemotrophic molecule that mediates axon outgrowth and orientation or neuronal migration during neuronal development. ${ }^{38-41}$ It is encoded by the NTN1 gene and is a laminin-related, secreted protein, which has an amino (N)-terminal type IV laminin repeat (domain IV), followed by three cysteine-rich epidermal growth-factor modules (domains V1, V2 and V3), and a positively charged carboxy-terminal domain. ${ }^{38}$

Another interesting observation was made in the p53regulated UNC5B signaling pathway. In the absence of netrin1 , infection with adenovirus containing the UNC5B gene induced remarkable levels of apoptosis in a glioblastoma cell line (U373MG) containing mutant p53, but was unable to induce apoptosis in the presence of netrin-1. ${ }^{11}$ This finding is consistent with the notion that UNC5B is a dependence receptor. Surprisingly, the addition of GST-fused netrin-1 to the culture medium strongly inhibited p53-induced apoptosis in vitro. Under conditions in which netrin-1 actively signaled, p53 was stably expressed and accumulated, but was functionally inactivated. ${ }^{11}$ Moreover, the induction of p21/ WAF1 and Bax was severely impaired under these conditions, implying dysfunction of the trans-activating activity of $p 53 .{ }^{11}$ This suggests that the netrin-UNC5B signaling inactivates p53 post-translationally.

How does netrin-UNC5B signaling block p53-induced apoptosis? It is likely that the suppression of p53-induced apoptosis cannot be explained solely in terms of the inhibition of UNC5B-induced apoptosis by netrin-1. This is because, as noted above, p53 regulates multiple apoptotic pathways, including the mitochondrial and death-receptor pathways. Although the mechanism is largely unknown, several clues have been provided by the findings for DCC, which is a dependence receptor and a receptor for netrin-1. The process might involve two steps: blocking the caspase-dependent cleavage of the intracellular region of the receptors and sending the antiapoptotic signal. In the first step, when netrin-1 binds to DCC and/or UNC5H, the receptors might interact with one another. ${ }^{42}$ In the case of p75/NTR, which was the first identified dependence receptor, its dimerization is required to block the proapoptotic effect. ${ }^{43}$ Thus, in the cases of DCC and the Unc5 family, the binding of netrin-1 might induce homo- or heterodimerization, resulting in structural changes in the intracellular region, which in turn might block caspase cleavage. In the second step, the phosphatidylinositol-3-kinase (PI3K)-AKT pathway might be of importance. In the case of DCC, DIP13- $\alpha$ / APPL mediates DCC-induced apoptosis by interacting with its intracellular domain. ${ }^{44}$ However, DIP13- $\alpha /$ APPL has also been shown to interact with AKT2, and to act as an adaptor protein between the $\mathrm{p} 110-\alpha$ catalytic subunit of PI3K and AKT2, thus implying a role in facilitating the activation of AKT2. ${ }^{45}$ AKT has a well-established role in antiapoptotic signaling pathways. ${ }^{46,47}$ When netrin- 1 interacts with DCC, DIP13- $\alpha /$ APPL dissociates and might subsequently activate AKT2 by interacting with AKT2 and PI3K, as an adaptor protein, sending the antiapoptotic signal that blocks the mitochondrial apoptotic proteins and the mitochondrial-derived apoptosome, and activating NF- $\kappa \mathrm{B}$ leading to the transcriptional activation of antiapoptotic genes. In the case of UNC5B, the mechanism by which netrin-1 blocks p53-dependent apoptosis is largely unclear. However, PI3K-AKT was previously shown to block p53-dependent apoptosis. ${ }^{48,49}$ It is therefore possible that this pathway might be involved in the phenomenon (Figure 2). Further investigation of these potential pathways will be necessary to clarify the mechanism of netrin- 1 antiapoptotic signaling.

Based on the existing evidence, netrin-1 might act as an oncogene under certain circumstances. If the expression of netrin-1 is elevated in human cancers, the p53-dependent apoptotic pathway will be inactivated through netrin-1 signaling. Recent data support this hypothesis. NTN1-transgenic mice were generated and analyzed in order to evaluate the in vivo role of netrin-1 in regulating apoptosis and tumorigenesis. ${ }^{50}$ In these mice, overexpression of netrin- 1 in the colon, where $\mathrm{DCC}$ and UNC5H2 are consistently expressed throughout the intestinal epithelium, reduced apoptosis in intestinal epithelial cells, leading to an increase in the spontaneous formation of colonic hyperplasia and adenoma. Moreover, NTN1-transgenic mice, on a genetic background from which the adenomatous polyposis coli gene had been knocked out, showed an increased rate of development of high-grade adenoma with focal adenocarcinoma. ${ }^{50}$ Thus, the role of netrin-1 as an oncogene might be crucial during the early stages of the adenoma-carcinoma sequence of colorectal cancers.

Is netrin-1 overexpressed in human colorectal cancers? Only two previous papers have reported the expression of netrin-1 in human cancers including brain tumors, neuroblastomas and prostate cancers. ${ }^{51,52}$ These studies showed, surprisingly, that netrin-1 was downregulated in these cancers. However, this unexpected observation could be explained by the fact that p53 is mutated in over half the cancers in which netrin-1's receptor, UNC5B, is not inducible by p53 in response to cellular stresses. In addition, DCC and UNC5H are frequently inactivated in human cancers. Therefore, elevated expression of netrin- 1 could be expected to be infrequent in human cancers, if it occurs at all. In human colorectal cancers, DCC and $\mathrm{UNC} 5 \mathrm{H}$, rather than their ligand netrin-1, are the principal targets for tumorigenesis. Consistent with this hypothesis, the study on NTN1-transgenic mice also revealed that netrin-1 expression was elevated in three out of 40 primary colorectal cancers in which DCC was also expressed, thus implying that the netrin-1 and DCC pathway was intact in these three cases. ${ }^{50}$ Further investigation will be necessary to clarify the precise role of netrin-1 in human tumorigenesis. 


\section{Life or Death: Another Pathway for the p53 Switch}

As noted above, if netrin-1 blocks p53-dependent apoptosis, this raises an important question: why does p53 activate the transcription of UNC5B? In the presence of netrin-1, the induction of UNC5B by p53 leads to cell survival, whereas in the absence of netrin-1, the induction of UNC5B by p53 leads to cell death. Given that p53 is crucial for the death or survival of cells in response to cellular stresses, the regulation of UNC5B alone as a receptor for netrin-1 does not appear compatible with the essential role of p53. An important observation concerning this issue is that the expression of netrin-1 is also directly regulated by p53 ( $\mathrm{N}$ Kitamura, $\mathrm{H}$ Nakanishi, C Tanikawa, Y Nakamura and H Arakawa, unpublished data). Thus, p53 might determine cell fate by regulating both netrin-1 and its receptor, UNC5B (Figure 3). For example, in order to activate the death pathway, p53 induces UNC5B but not netrin-1. By contrast, in order to activate the survival pathway, p53 induces both UNC5B and netrin-1. Why would a cell have evolved this form of dual control?

The death signal induced by p53 is well established and has been investigated in a number of excellent studies. ${ }^{5}$ By contrast, the survival signal induced by $\mathrm{p} 53$ has not yet been studied. Why does p53 send a survival signal? The reason is still unclear. However, if we consider p53 to be a pivotal checkpoint protein, which determines cell fate after various cellular stresses, it is likely to be required both for inducing death and for prolonging cell survival. Moreover, if we see p53's primary role as protecting cells from stress, it might allow the damaged cells to live by sending a strong survival signal, and triggering their repair by inducing the transcription of various repair-related genes. Consistent with this idea, p53 is known to activate the transcription of many cell survivalrelated genes including $p 53 R 2,{ }^{17,53} \mathrm{XPC},{ }^{54} \mathrm{DDB} 2,{ }^{55} \mathrm{CSR}^{56}$ and $A L D H 4 .^{25}$ Strong survival signals are well known to be delivered to cells by soluble ligands binding to cell-surface receptors, for example, by growth factors and their receptors, or by direct interactions with neighboring cells or the extracellular matrix, which activate the PI3K-AKT pathway. ${ }^{57}$ By delivering strong survival signals through the PI3K-AKT pathway, p53 could downregulate all three p53-dependent pathways leading to apoptosis through the transcriptional induction of netrin-1 and its receptor UNC5B, and so protect cells from cellular stresses. Moreover, the transcriptional activation of netrin-1 by p53 could send a survival signal not only for the cell itself but also for surrounding cells, by providing a soluble molecule that could act as a paracrine signal, and result in the survival and protection of a group of cells under stress.

Although the details of the mechanism remain unclear, it is possible that activating the PI3K-AKT pathway through the transcriptional induction of netrin-1 and its receptor UNC5B is the most powerful way to block cell-death signaling and ensure cell survival. ${ }^{48,49,57}$ In support of this theory, a number of somatic oncogenic mutations of the PIK3CA gene, which encodes the $p 110-\alpha$ catalytic subunit, have recently been

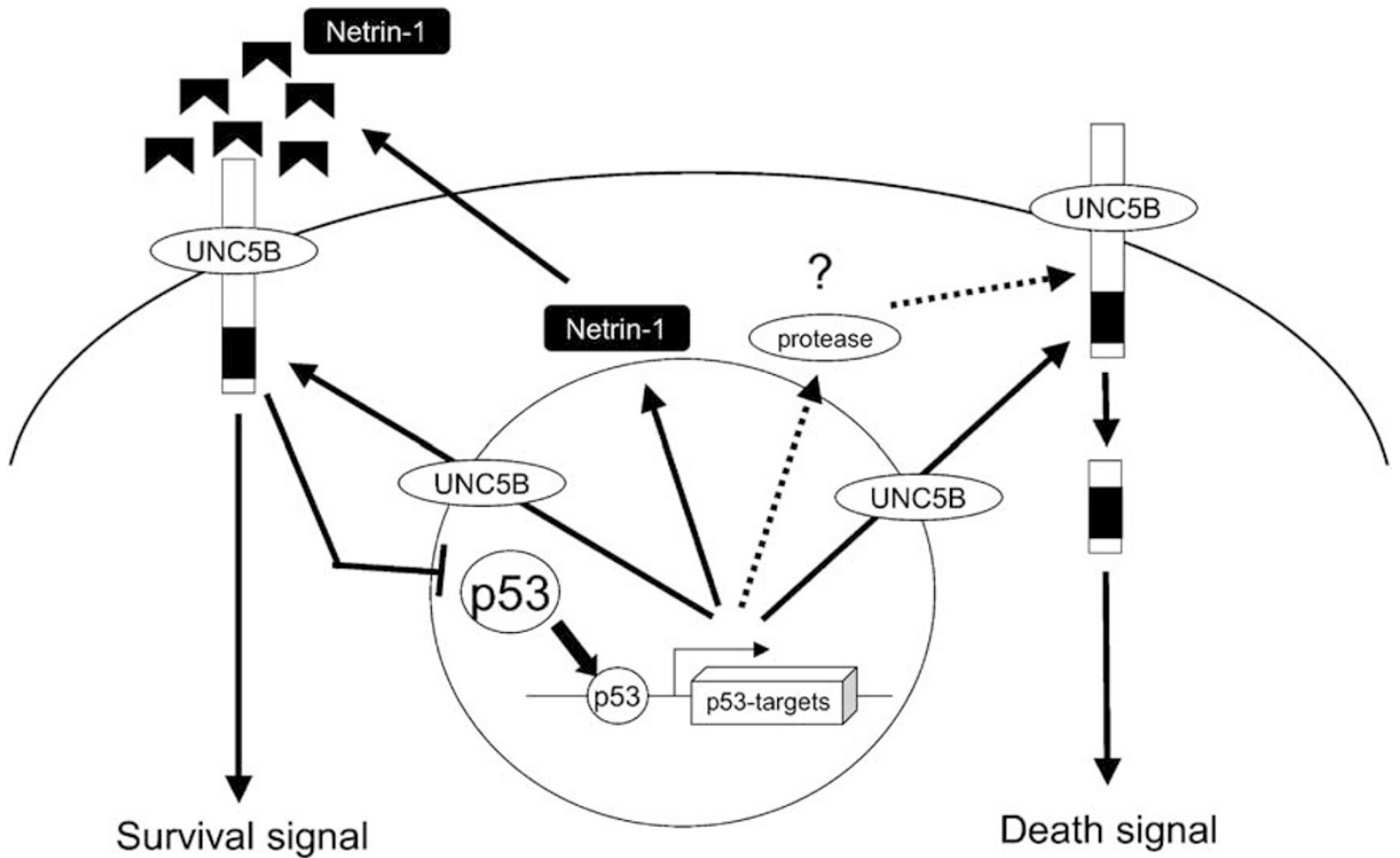

Figure 3 A new pathway for the p53 life or death switch. p53 might determine cell fate through the transcriptional regulation of netrin-1 and UNC5B under physiological conditions. In order to eliminate a cell with DNA damage, p53 activates the transcription of UNC5B. The protein is then expressed and localized at the cell membrane, leading to the cleavage of the intracellular domain and apoptosis induction. Conversely, in order for the cell to survive, p53 activates the transcription of both netrin-1 and UNC5B. Netrin-1 is expressed and secreted, and binds to UNC5B, thereby sending the survival signal. This signal blocks p53-dependent apoptosis. An unknown protease or caspase might be induced by p53 to trigger UNC5B-induced apoptosis by cleaving the intracellular domain of UNC5B. In this model, the expression of UNC5B alone at the cell membrane does not always induce apoptosis 
reported in human cancers, ${ }^{58}$ suggesting that activation of the PI3K pathway might block p53-dependent apoptosis. Further investigation of this potential control mechanism for UNC5B and netrin- 1 by $\mathrm{p} 53$ will be necessary before a conclusive mechanism can be determined.

\section{Other Axon-Guidance-Related Molecules: Alteration in Human Cancer and p53-Dependent Regulation}

Interestingly, several axon-guidance-related genes, NTN1, DCC, UNC5H, SEMA3B, SEMA3F, SLIT2, ROBO1 and $E P H B 2$, are genetically and epigenetically inactivated in a number of human cancers, implying that all four pathways involved in axon guidance are downregulated during the tumorigenic process. ${ }^{59}$ In addition to netrin-1 and UNC5B, SEMA3B and EPHA2 were previously reported to be p53inducible genes. ${ }^{60,61}$ Moreover, UNC5A, SEMA3F, SLIT2 and EPHB2 are p53 inducible under certain conditions (M Futamura, $\mathrm{H}$ Kamino and $\mathrm{H}$ Arakawa, unpublished data). ${ }^{59}$ This implies that all four pathways are regulated by tumor suppressor p53.

SEMA3B and SEMA3F were originally identified as candidate tumor-suppressor genes on chromosome 3p21.3, in a region that undergoes allelic loss in $\sim 80 \%$ of primary lung cancer and homozygous deletions in several small lung cancer cell lines. ${ }^{62}$ The sequences of these genes indicated that the proteins they encoded were two additional members of the human semaphorin family, semaphorin 3B and 3F, belonging to class 3 semaphorins, whose receptors are the neuropilins. Following this report, $S E M A 3 B$ was observed to be hypermethylated in lung cancers, and several point mutations were identified along with loss of heterozygosity $(\mathrm{LOH})$ in the region. ${ }^{63}$ Moreover, the enforced expression of $S E M A 3 B$ in lung cancers normally lacking semaphorin 3B expression induced growth suppression and apoptosis. ${ }^{64,65}$ Semaphorin 3F was also shown to suppress tumor formation in nude mice; this effect was thought to be due to the inhibition of tumor angiogenesis, ${ }^{66-69}$ as a result of semaphorin $3 \mathrm{~F}$ binding to and activating its receptor, neurophilin-2, which then inhibits the VEGF- and bFGF-induced proliferation of vascular endothelial cells.

The SLIT-ROBO interaction mediates the repulsive cues on axons and growth cones during neural development and is also thought to be involved in the cell migration of myoblasts and leukocytes. SLIT2 is frequently inactivated by $\mathrm{LOH}$ and hypermethylation in colorectal cancers, and the introduction of SLIT2 suppresses tumor growth. ${ }^{70,71}$ ROBO1, which is a receptor for SLIT2, is also thought to be a candidate tumorsuppressor gene at chromosome 3p12. ROBO1 is frequently inactivated in lung, kidney and breast cancers by $\mathrm{LOH}$ and hypermethylation. ${ }^{72,73}$ Moreover, exon 2 of ROBO1/DUTT1 was found to be homozygously deleted in two lung cancer cell lines and one breast cancer cell line. ${ }^{74}$ Ectopic expression of SLIT2 was suggested to induce the growth suppression of several cancer cell lines by inducing apoptosis. ${ }^{70,71}$ However, the mechanism by which the SLIT-ROBO signaling suppresses tumor growth remains largely unclear.
The EPHB2 gene encodes the ephrin receptor EPHB2 and was originally isolated from a cDNA expression library as a kinase overexpressed in human cancers. ${ }^{75}$ Ephrin and $\mathrm{EPH}$ receptor signaling is involved at various stages of the neuronal developmental, including axon-guidance and neural-crest migration, vascular modeling and cell positioning in the intestinal epithelium. Recently, frameshift, splice site, missense and nonsense mutations of EPHB2 have been found in human prostate cancers. ${ }^{76}$ Moreover, overexpression of wt EPHB2, but not mutant EPHB2, suppressed the clonogenic growth of a prostate cancer cell line, DU145, with biallelic inactivation (nonsense mutations and loss of the wt allele) of EPHB2. Interestingly, EPHB2 maps to chromosome 1p36.1, where deletions are observed frequently in many cancers, including neuroblastomas. Although the mechanism for tumor suppression through Ephrin and EPH receptor signaling remains to be elucidated, these data strongly support a possible role of EPHB2 as a tumor-suppressor gene.

The roles of semaphorins, slits, ephrins and their receptors in tumorigenesis have been well characterized and previously reviewed, with respect to cell migration during cancer metastasis and angiogenesis during the neovasculization promoted by oncogenes. ${ }^{77-82}$ However, as noted above, recent studies have clearly demonstrated their roles as tumorsuppressor genes. The mechanism for tumor suppression by semaphorins, slits, ephrins and their receptors is largely unknown and, together with apoptosis, remains a matter for future investigation. The observed inactivation in cancer and the p53-dependent regulation strongly suggest that important common mechanisms are involved in both axon guidance and tumorigenesis. $^{59}$

\section{Conclusions and Future Directions}

We have demonstrated that both UNC5B and netrin-1 are directly regulated by the tumor suppressor p53, and provide a new mechanism for p53's switch between cell death or cell survival. The signaling pathways for UNC5Binduced apoptosis and netrin-1-dependent antiapoptosis are largely unknown. However, the cleavage of UNC5B by caspase or another unidentified protease seems to be indispensable for UNC5B-induced apoptosis, and two possible proteins, DAPK and NRAGE, might mediate this pathway. By contrast, the PI3K-AKT pathway might be involved in signaling in netrin-1-regulated antiapoptosis.

Important questions still remain to be addressed. If UNC5B requires caspase cleavage to induce apoptosis, how is a caspase or other protease activated before the cleavage of UNC5B? What is the initiator of UNC5B-induced apoptosis? One possibility is that another trigger is needed to activate an unknown protease or caspase. Even in the absence of netrin1 , the expression of UNC5B alone at the cellular membrane does not always induce apoptosis. Another trigger might respond to various cellular stresses, leading to the recruitment and activation of an unknown protease or caspase (Figure 3). One attractive candidate for a trigger is p53. In fact, we observed that caspase-1, which is one of the p53-target 


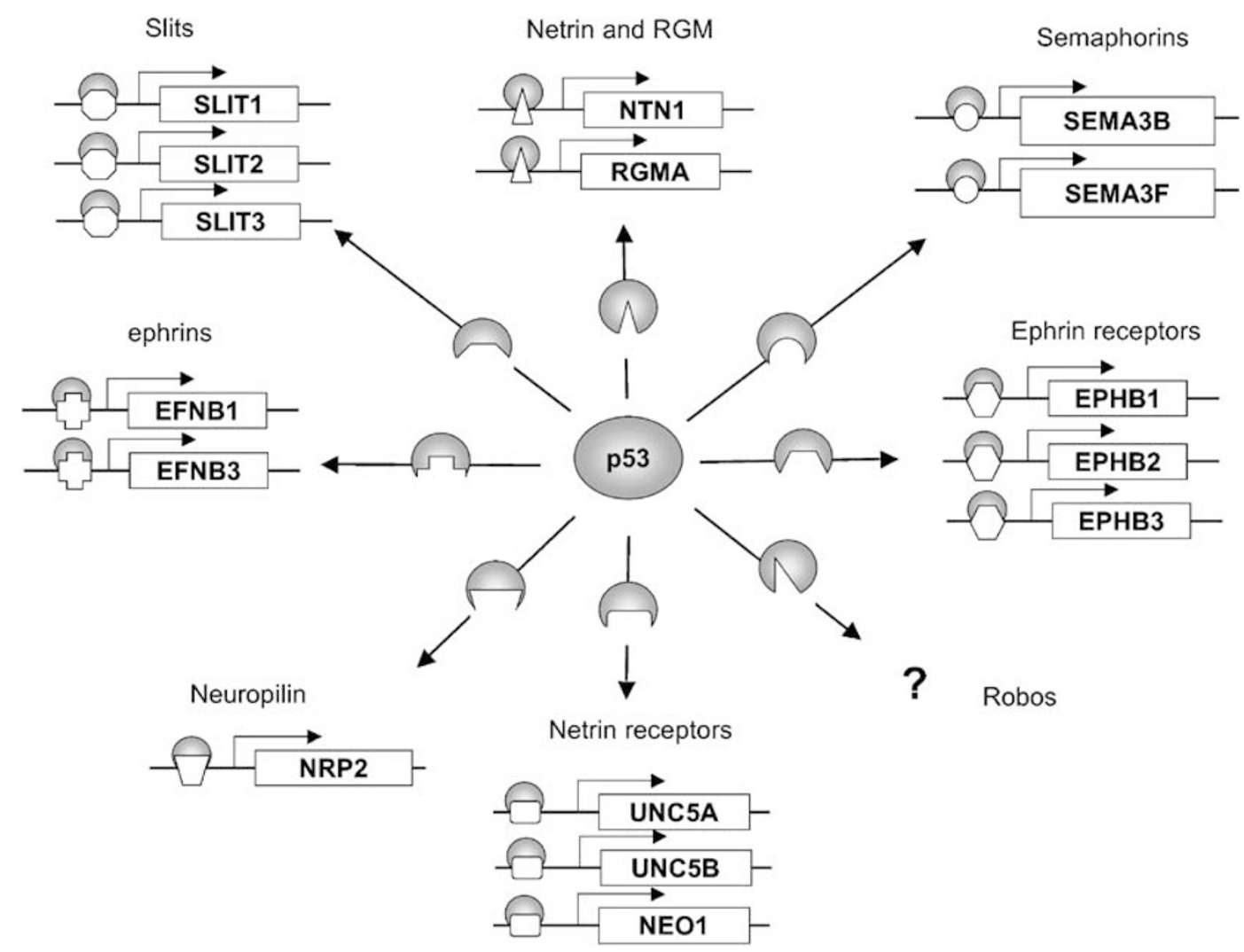

Figure 4 p53-regulated expression of various axon-guidance molecules. p53 regulates transcription of the netrin and RGM (NTN1 and RGMA) and their receptors (UNC5A, UNC5B and NE01), the semaphorins (SEMA3B and SEMA3F) and their receptor neuropilin-2 (NRP2), the slits (SLIT1, SLIT2 and SLIT3), and the ephrins (EFNB1 and EFNB3) and their receptors (EPHB1, EPHB2 and EPHB3). This suggests that p53 has a role in all four of the pathways that are involved in axon guidance. In response to various cellular stresses, p53 might alter its structure by a combination of protein modifications such as phosphorylation, acetylation, methylation, sumoylation, ubiquitination and glycosylation. Each p53 configuration might correspond to the sequence of a group of target genes, thereby regulating a number of axonguidance molecules. Netrins and their receptors are involved in p53-dependent apoptosis, whereas the functions of other molecules in p53-regulated tumor suppression remain largely unknown

genes, caused the cleavage of wt-UNC5B but not mt-UNC5B (D412N), at the caspase-cleavage site (Asp412; N Kitamura and $\mathrm{H}$ Arakawa, unpublished data). p53 might trigger UNC5Binduced apoptosis through the transcriptional activation of caspase-1 in vivo.

As noted, several axon-guidance molecules are inactivated in human cancers and are p53 inducible under certain conditions. In addition, we now realize that $R G M A$ (encoding RGM), NEO1 (encoding neogenin), NRP2 (encoding neurophilin-2), SLIT1, SLIT3, EFNB1, EFNB3, EPHB1 and EPHB3 are also p53 inducible, although these molecules have not yet been shown to be altered in cancers (M Futamura, H Kamino and $\mathrm{H}$ Arakawa, unpublished data; Figure 4). Thus, p53 regulates all four axon-guidance pathways: netrins, semaphorins, SLITs and ephrins. This review has shown that netrin is likely to be involved in apoptosis regulation, with its receptors acting as dependence receptors. However, the mechanisms for tumor suppression by the other pathways are largely unknown. What are the functions of semaphorins, SLITs and ephrins as p53-regulated genes? Are these molecules involved in p53-regulated tumor suppression? Further investigation of these molecules will be necessary to understand the roles of these important pathways in tumorigenesis. $^{59}$

\section{Acknowledgements}

This work was supported by grants from the Ministry of Health, Labour and Welfare, Japan and by grants from the Ministry of Education, Culture, Sports, Science and Technology, Japan.

\section{References}

1. Vogelstein B, Lane D and Levine AJ (2000) Surfing the p53 network. Nature 408: $307-310$

2. Vousden KH (2002) Live or let die: the cell's response to p53. Nat. Rev. Cancer 2: $594-604$

3. Nakamura $Y(2004)$ Isolation of p53-target genes and their functional analysis. Cancer Sci. 95: 7-11

4. Oda K, Arakawa H, Tanaka T, Matsuda K, Tanikawa C, Mori T, Nishimori H, Tamai K, Tokino T, Nakamura Y and Taya Y (2000) p53AIP1, a potential mediator of p53-dependent apoptosis, and its regulation by Ser-46phophorylated p53. Cell 102: 849-862

5. Vousden KH (2000) p53: Death star. Cell 103: 691-694

6. Yu TW and Bargmann $\mathrm{Cl}$ (2001) Dynamic regulation of axon guidance. Nat. Neurosci. 4: 1169-1176

7. Bredesen DE, Mehlen P and Rabizaheh S (2004) Apoptosis and dependence receptors: a molecular basis for cellular addiction. Physiol. Rev. 84: 411-430

8. Mehlen P and Bredesen DE (2004) The dependence receptor hypothesis. Apoptosis 9: 37-49 
9. Mehlen P, Rabizadeh S, Snipas SJ, Assa-Munt N, Salvesen GS and Bredesen DE (1998) The DCC gene product induces apoptosis by a mechanism requiring receptor proteolysis. Nature 395: 801-804

10. Llambi $F$, Causeret F, Bloch-Gallego $E$ and Mehlen $P$ (2001) Netrin-1 acts as a survival factor via its receptors UNC5H and DCC. EMBO J. 20: 2715-2722

11. Tanikawa C, Matsuda K, Fukuda S, Nakamura $Y$ and Arakawa H (2003) p53RDL1 regulates p53-dependent apoptosis. Nat. Cell Biol. 5: 216-223

12. El-Deiry W, Tokino T, Velculescu VE, Levy DB, Parsons R, Trent JM, Lin D, Mercer W, Kinzler KW and Vogelstein B (1993) WAF1, a potential mediator of p53 tumor suppression. Cell 75: 817-825

13. Miyashita $T$ and Reed JC (1995) Tumor suppressor p53 is a direct transcriptional activator of the human BAX gene. Cell 80: 293-299

14. Buckbinder L, Talbott R, Velasco-Miguel S, Takenaka I, Faha B, Seizinger BR and Kley N (1995) Induction of the growth inhibitor IGF-binding protein 3 by p53. Nature 377: 646-649

15. Nishimori $H$, Shiratsuchi T, Urano T, Kimura $Y$, Kiyono K, Tatsumi K, Yoshida S, Ono M, Kuwano M, Nakamura Y and Tokino T (1997) A novel brain-specific p53-target gene, BAl1, containing thrombospondin type 1 repeats inhibits experimental angiogenesis. Oncogene 15: 2145-2150

16. Kastan MB, Zhan Q, El-Deiry WS, Carrier F, Jacks T, Walsh WV, Plunkett BS, Vogelstein B and Fornance AJ (1992) A mammalian cell cycle checkpoin pathway utilizing p53 and GADD45 is defective in ataxia-telangiectasia. Cell 71: 587-597

17. Tanaka H, Arakawa H, Yamaguchi T, Shiraishi K, Fukuda S, Matsui K, Takei Y and Nakamura $Y(2000)$ A ribonucleotide reductase gene involved in a p53dependent cell-cycle checkpoint for DNA damage. Nature 404: 42-49

18. Barak $Y$, Juven T, Haffner R and Oren M (1993) Mdm2 expression is induced by wild type p53 activity. EMBO J. 12: 461-468

19. Oda E, Ohki R, Murasawa H, Nemoto J, Shibue T, Yamashita T, Tokino T, Taniguchi T and Tanaka N (2000) Noxa, a BH3-only member of the Bcl-2 family and candidate mediator of p53-induced apoptosis. Science 288: 1053-1058

20. Nakano K and Vousden KH (2001) PUMA, a novel pro-apoptotic gene, is induced by p53. Mol. Cell 7: 683-692

21. Yu J, Zhang L, Hwang PM, Kinzler KW and Vogelstein B (2001) PUMA induces the rapid apoptosis of colorectal cancer cells. Mol. Cell 7: 673-682

22. Moroni MC, Hickman ES, Denchi EL, Caprara G, Colli E, Cecconi F, Muller H and Helin K (2001) Apaf-1 is a key transcriptional target for E2F and p53. Nat. Cell Biol. 3: 552-558

23. Polyak K, Xia Y, Zweier JL, Kinzler KW and Vogelstein B (1997) A model for p53-induced apoptosis. Nature 389: 300-305

24. Donald SP, Sun XY, Hu CA, Yu J, Mei JM, Valle D and Phang JM (2001) Proline oxidase, encoded by p53-induced gene- 6 , catalyzes the generation of proline-dependent reactive oxygen species. Cancer Res. 61: 1810-1815

25. Yoon KA, Nakamura Y and Arakawa H (2004) Identification of ALDH4 as a p53inducible gene and its protective role in cellular stresses. J. Hum. Genet. 49: $134-140$

26. Hwang PM, Bunz F, Yu J, Rago C, Chan TA, Murphy MP, Kelso GF, Smith RA, Kinzler KW and Vogelstein B (2001) Ferredocin reductase affects p53dependent, 5-fluorouracil-induced apoptosis in colorectal cancer cells. Nat. Med. 7: 1111-1117

27. liizumi $M$, Arakawa $H$, Mori $T$, Ando $A$ and Nakamura $Y$ (2002) Isolation of a novel gene, $C A B C 1$, encoding a mitochondrial protein that is highly homologous to yeast activity of bc1 complex. Cancer Res. 62: 1246-1250

28. Chipuk JE, Kuwana T, Bouchier-Hayes L, Droin NM, Newmeyer DD, Schuler M and Green DR (2004) Direct activation of Bax by p53 mediates mitochondrial membrane permeabilization and apoptosis. Science 303: 1010-1014

29. Owen-Schaub LB, Zhang W, Cusack JC, Angelo LS, Santee SM, Fujiwara T, Roth JA, Deisseroth AB, Zhang WW, Kruzel E and Radinsky R (1995) Wild-type human $\mathrm{p53}$ and temperature sensitive mutant induce Fas/APO-1 expression. Mol. Cell. Biol. 15: 3032-3040

30. Wu GS, Burns TF, McDonald III ER, Jiang W, Meng R, Krantz ID, Kao G, Gan DD, Zhou JY, Muschel R, Hamilton SR, Spinner NB, Markowitz S, Wu G and El-Deiry WS (1997) KILLER/DR5 is a DNA damage inducible p53-regulated death receptor gene. Nat. Genet. 17: 141-143

31. Fei P, Bernhard EJ and El-Deiry WS (2002) Tissue-specific induction of p53targets in vivo. Cancer Res. 62: 7316-7327

32. Leonardo ED, Hinck L, Masu M, Keino-Masu K, Ackerman SL and TessierLavigne M (1997) Vertebrate homologues of $C$. elegans UNC-5 are candidate netrin receptors. Nature 386: 833-838
33. Tessier-Lavigne M and Goodman CS (1996) The molecular biology of axon guidance. Science 274: 1123-1133

34. Mehlen P and Bredesen DE (2003) Meeting report: cellular dependence - old concept, new mechanisms. Sci. STKE 2003: pe55

35. Williams ME, Strickland $P$, Watanabe $K$ and Hinck L (2003) UNC5H1 induces apoptosis via its juxtamembrane region through an interaction with NARGE. J. Biol. Chem. 278: 17483-17490

36. Hedgecook EM, Culotti JG and Hall DH (1990) The unc-5, unc- 6 and unc-40 genes guide circumferential migration of pioneer axons and mesodermal cells on the epidermis of $C$. elegans. Neuron 2: 61-85

37. Ishii N, Wadsworth WG, Stern BD, Culotti JG and Hedgecook EM (1992) UNC-6, a laminin-related protein, guides cell and pioneer axon migrations in C. elegans. Neuron 9: 873-881

38. Serafini T, Kennedy TE, Galko MJ, Mirzayan C, Jessell TM and TessierLavigne M (1994) The netrins define a family of axon outgrowth-promoting proteins homologous to $C$. elegans UNC-6. Cell 78: 409-424

39. Kennedy TE, Serafini T, de la Torre JR and Tessier-Lavigne M (1994) Netrins are diffusible chemotropic factors for commissural axons in the embryonal spinal cord. Cell 78: 425-435

40. Chan SS, Zheng H, Su MW, Wilk R, Killeen MT, Hedgecock EM and Culotti JG (1996) UNC40, a C. elegans homolog of DCC (deleted in colorectal cancer), is required in motile cells responding to UNC-6 netrin cues. Cell 87 187-195

41. Serafini T, Colamarino SA, Leonardo ED, Wang H, Beddington R, Skarnes WC and Tessier-Lavigne M (1996) Netrin-1 is required for commissural axon guidance in the developing vertebrate nervous system. Cell 87: 1001-1014

42. Hong K, Hinck L, Nishiyama M, Poo MM, Tessier-Lavigne M and Stein E (1999) A ligand-gated association between cytoplasmic domains of UNC5 and DCC family receptors converts Netrin-induced growth cone attraction to repulsion. Cell 97: 927-941

43. Wang JJ, Rabizadeh S, Tasinato A, Sperandio S, Ye X, Green M, Assa-Munt $\mathrm{N}$, Spencer D and Bredesen DE. (2000) Dimerization-dependent block of the proapoptotic effect of p75/NTR. J. Neurosci. Res. 60: 587-593

44. Liu J, Yao F, Wu R, Morgan M, Thorburn A, Finley Jr RL and Chen YQ (2002) Mediation of the DCC apoptotic signal by DIP13alpha. J. Biol. Chem. 277: $26281-26285$

45. Mitsuuchi $Y$, Johnson SW, Sonoda G, Tanno S, Golemis EA and Testa JR (1999) Identification of a chromosome 3p14.3-21.1 gene, APPL, encoding an adaptor molecule that interacts with the oncoprotein-serine/threonine kinase AKT2. Oncogene 18: 4891-4898

46. Dudek H, Datta SR, Franke TF, Birnbaum MJ, Yao R, Cooper GM, Segal RA, Kaplan DR and Greenberg ME (1997) Regulation of neuronal survival by the serine-threonine protein kinase Akt. Science 275: 661-665

47. Hemmings BA (1997) Akt signaling: linking membrane events to life and death decisions. Science 275: 628-630

48. Sabbatini P and McCormick F (1999) Phosphoinositide 3-OH kinase (PI3K) and PKB/Akt delay the onset of p53-mediated transcriptional dependent apoptosis. J. Biol. Chem. 274: 24263-24269

49. Yamaguchi A, Tamatani M, Matsuzaki $H$, Namikawa $K$, Kiyama $H$, Vitek MP, Mitsuda N and Tohyama M (2001) Akt activation protects hippocampal neurons from apoptosis by inhibiting transcriptional activity of p53. J. Biol. Chem. 276: 5256-5364

50. Mazelin L, Bernet A, Bonod-Bidaud C, Pays L, Arnaud S, Gespach C, Bredesen DE, Scoazec JY and Mehlen P (2004) Netrin-1 controls colorectal tumorigenesis by regulating apoptosis. Nature $431: 80-84$

51. Meyerhardt JA, Caca K, Eckstrand BC, Hu G, Lengauer C, Banavali S, Look AT and Fearon ER (1999) Netrin-1: interaction with deleted in colorectal cancer (DCC) and alterations in brain tumors and neuroblastomas. Cell Growth Differ. 10: $35-42$

52. Latil A, Chene L, Cochant-Priollet B, Mangin P, Fournier G, Berthon P and Cussenot $O$ (2003) Quantification of expression of netrins, slits and their receptors in human prostate tumors. Int. J. Cancer 103: 306-315

53. Kimura T, Takeda S, Sagiya Y, Gotoh M, Nakamura Y and Arakawa H (2003) Impaired function of p53R2 in Rrm2b-null mice causes severe renal failure through attenuation of dNTP pools. Nat. Genet. 34: 440-445

54. Adimoolam S and Ford JM (2002) p53 and DNA damage-inducible expression of the xeroderma pigmentosum group $\mathrm{C}$ gene. Proc. Natl. Acad. Sci. USA 99: $12985-12990$ 
55. Hwang BJ, Ford JM, Hanawalt PC and Chu G (1999) Expression of the p48 xeroderma pigmentosum gene is p53-dependent and is involved in global genomic repair. Proc. Natl. Acad. Sci. USA 96: 424-428

56. Han HJ, Tokino T and Nakamura Y (1998) CSR, a scavenger receptor-like protein with a protective role against cellular damage caused by UV irradiation and oxidative stress. Hum. Mol. Genet. 7: 1039-1046

57. Vivanco I and Sawyers CL (2002) The phosphatidylinositol 3-kinase-Akt pathway in human cancer. Nat. Rev. Cancer 2: 489-501

58. Samuels Y, Wang Z, Bardelli A, Silliman N, Ptak J, Szabo S, Yan H, Gazdar A, Powell SM, Riggins GJ, Willson JK, Markowitz S, Kinzler KW, Vogelstein B and Velculescu VE (2004) High frequency of mutations of the PIK3CA gene in human cancers. Science 304: 554

59. Arakawa $\mathrm{H}$ (2004) Netrin-1 and its receptors in tumorigenesis. Nat. Rev. Cancer 4: 978-987

60. Ochi K, Mori T, Toyama $\mathrm{Y}$, Nakamura $\mathrm{Y}$ and Arakawa $\mathrm{H}$ (2002) Identification of semaphorin3B as a direct target of p53. Neoplasia 4: 82-87

61. Dohn M, Jiang $J$ and Chen $X$ (2001) Receptor tyrosine kinase EphA2 is regulated by p53-family proteins and induces apoptosis. Oncogene 20: 6503-6515

62. Sekido Y, Bader S, Latif F, Chen JY, Duh FM, Wei MH, Albanesi JP, Lee CC Lerman MI and Minna JD (1996) Human semaphorins A(V) and IV reside in the 3p21.3 small cell lung cancer deletion region and demonstrate distinct expression patterns. Proc. Natl. Acad. Sci. USA 93: 4120-4125

63. Kuroki T, Trapasso F, Yendamuri S, Matsuyama A, Alder H, Williams NN, Kaiser LR and Croce CM (2003) Allelic loss on chromosome 3p21.3 and promoter hypermethylation of semaphorin $3 \mathrm{~B}$ in non-small cell lung cancer. Cancer Res. 63: 3352-3355

64. Tomizawa Y, Sekido Y, Kondo M, Gao B, Yokota J, Roche J, Drabkin H, Lerman MI, Gazdar AF and Minna JD (2001) Inhibition of lung cancer cell growth and induction of apoptosis after reexpression of 3p21.3 candidate tumor suppressor gene SEMA3B. Proc. Natl. Acad. Sci. USA 98: 13954-13959

65. Tse C, Xiang RH, Bracht T and Naylor SL (2002) Human semaphorin 3B (SEMA3B) located at chromosome 3p21.3 suppresses tumor formation in an adenocarcinoma cell line. Cancer Res. 62: 542-546

66. Xiang R, Davalos AR, Hensel CH, Zhou XJ, Tse C and Naylor SL (2002) Semaphorin $3 F$ gene from human $3 p 21.3$ suppresses tumor formation in nude mice. Cancer Res. 62: 2637-2643

67. Kessler O, Shraga-Heled N, Lange T, Gutmann-Raviv N, Sabo E, Baruch L, Machluf M and Neufeld G (2004) Semaphorin-3F is an inhibitor of tumor angiogenesis. Cancer Res. 64: 1008-1015

68. Brambilla E, Constantin B, Drabkin H and Roche J (2000) Semaphorin SEMA3F localization in malignant human lung and cell lines: a suggested role in cell adhesion and cell migration. Am. J. Pathol. 156: 939-950

69. Lantuejoul S, Constantin B, Drabkin H, Brambilla C, Roche J and Brambilla E (2003) Expression of VEGF, semaphoring SEMA3F, and their common receptors neuropilins NP1 and NP2 in preinvasive bronchial lesions, lung tumors, and cell lines. J. Pathol. 200: 336-347

70. Dallol A, Morton D, Maher ER and Latif F (2003) SLIT2 axon guidance molecule is frequently inactivated in colorectal cancer and suppresses growth of colorectal carcinoma cells. Cancer Res. 63: 1054-1058

71. Dallol A, Da Silva NF, Viacava P, Minna JD, Bieche I, Maher ER and Latif $F$ (2002) SLIT2, a human homologue of the Drosophila slit2 gene, has tumor suppressor activity and is frequently inactivated in lung and breast cancers. Cancer Res. 62: 5874-5880

72. Huebner K (2001) Tumor suppressors on 3p: a neoclassic quartet. Proc. Natl. Acad Sci. USA 98: 14763-14765
73. Dallol A, Forgacs E, Martinez A, Sekido Y, Walker R, Kishida T, Rabbitts P, Mahler ER, Minna JD and Latif $F$ (2002) Tumour specific promoter region methylation of the human homologue of the Drosophila roundabout gene (ROBO1) in human cancers. Oncogene 21: 3020-3038

74. Sundaresan V, Chung G, Heppell-Parton A, Xiong J, Grundy C, Roberts I, James L, Cahn A, Bench A, Douglas J, Minna J, Sekido Y, Lerman M, Latif F, Bergh J, Li H, Lowe N, Ogilvie D and Rabbitts P (1998) Homozygous deletions at 3p12 in breast and lung cancer. Oncogene 17: 1723-1729

75. Ikegaki N, Tang XX, Liu XG, Biegel JA, Allen C, Yoshioka A, Sulman EP, Brodeur GM and Pleasure DE (1995) Molecular characterization and chromosomal localization of DRT (EPHT3): a developmentally regulated human protein-tyrosine kinase gene of the EPH family. Hum. Mol. Genet. 4: 2033-2045

76. Huusko P, Ponciano-Jackson D, Wolf M, kiefer JA, Azorsa DO, Tuzmen S, Weaver D, Robbins C, Moses T, Allinen M, Hautaniemi S, Chen Y, Elkahloun A, Basik M, Bova GS, Bubendorf L, Lugli A, Sauter G, Schleutker J, Ozcelik H, Elowe S, Pawson T, Trent JM, Carpten JD, Kallioniemi OP and Mousses S (2004) Nonsense-mediated decay microarray analysis identifies mutations of EPHB2 in human prostate cancer. Nat. Genet. 36: 979-983

77. Trusolino L and Comoglio PM (2002) Scatter-factor and semaphoring receptors: cell signaling for invasive growth. Nat. Rev. Cancer 2: 289-299

78. Tamagnone $L$ and Comoglio PM (2004) To move or not to move? EMBO Rep. 5: $356-361$

79. Nakada M, Niska JA, Miyamori H, McDonough WS, Wu J, Sato H and Berens ME (2004) The phosphorylation of EphB2 receptor regulates migration and invasion of human glioma cells. Cancer Res. 64: 3179-3185

80. Roush W (1998) Receptor links blood vessels, axons. Science 279: 2042

81. Liu ZJ and Herlyn M (2004) Slit-Robo: neuronal guides signal in tumor angiogenesis. Cancer Cell 4: 1-2

82. Wang B, Xiao Y, Ding BB, Zhang N, Yuan X, Gui L, Qian KX, Duan S, Chen Z, Rao $Y$ and Geng JG (2004) Induction of tumor angiogenesis by Slit-Robo signaling and inhibition of cancer growth by blocking Robo activity. Cancer Cell 4: $19-29$

83. Banin S, Moyal L, Shieh S, Taya Y, Anderson CW, Chessa L, Smorodinsky NI, Prives C, Reiss Y, Shiloh Y and Ziv Y (1998) Enhanced phosphorylation of p53 by ATM in response to DNA damage. Science 281: 1674-1677

84. Canman CE, Lim DS, Cimprich KA, Taya Y, Tamai K, Sakaguchi K, Appella E, Kastan MB and Siliciano JD (1998) Activation of the ATM kinase by ionizing radiation and phosphorylation of p53. Science 281: 1677-1679

85. Hirao A, Kong YY, Matsuoka S, Wakeham A, Ruland J, Yoshida H, Liu D, Elledge SJ and Mak TW (2000) DNA damage-induced activation of p53 by the checkpoint kinase Chk2. Science 287: 1824-1827

86. Keller DM, Zeng X, Wang Y, Zhang QH, Kapoor M, Shu H, Goodman R, Lozano G, Zhao $Y$ and Lu H (2001) A DNA damage-induced p53 serine 392 kinase complex contains CK2, hSpt16, and SSRP1. Mol. Cell 7: 283-292

87. Okamura S, Arakawa H, Tanaka T, Nakanishi H, Ng CC, Taya Y, Monden M and Nakamura $Y$ (2001) p53DINP1, a p53-inducible gene, regulates p53dependent apoptosis. Mol. Cell 8: 85-94

88. Shikama N, Lee CW, France S, Delavaine L, Lyon J, Krstic-Demonacos M and La Thangue NB (1999) A novel cofactor for p300 that regulates the p53 response. Mol. Cell 4: 365-376

89. Samuels-Lev Y, O'Connor DJ, Bergamaschi D, Trigiante G, Hsieh JK, Zhong S, Campargue I, Naumovski L, Crook T and Lu X (2001) ASPP proteins specifically stimulate the apoptotic function of p53. Mol. Cell 8: $781-794$ 